\title{
A ocupação do Congresso: contra o quê lutam os índios? ${ }^{1}$
}

ARTIONKA CAPIBERIBE I e OIARA BONILLA II

"Ser indigena significa que el proyecto de Estado nación no triunfó, [..], que el territorio no es único, que la lengua no es única y que no hay una sola ciudadanía."

(Gladys Tzul, liderança maya e cientista política)

$\mathrm{P}$ OLíTICA e modelo econômico. É nesse âmbito que, há séculos, os direitos indígenas vêm sendo tratados. ${ }^{2} \mathrm{O}$ debate contemporâneo é mais uma reedição da história que se instaurou com a invenção da América pela invasão europeia, e que vem obrigando as populações indígenas a uma criatividade constante para dar conta da relação com esse Outro pouco complacente e muitas vezes implacável. ${ }^{3}$

O que há de diferente hoje é a forma assertiva com que os índios têm se colocado no cenário político nacional e internacional, apresentando-se como porta-vozes de suas causas e atuando seja de forma institucionalizada por meio de suas associações, da ocupação de postos políticos em agências governamentais e em organizações não governamentais, seja valendo-se de um discurso cosmopolítico sustentado na oratória de alguns homens e mulheres cuja sabedoria tem a capacidade efetiva de transbordar as fronteiras de suas sociedades de origem, como o Yanomami Davi Kopenawa, o Kayapó Raoni Metuktire e a Guajajara Sônia Bone Guajajara. ${ }^{4}$ É por meio da fala - que, como foi pioneiramente apontado por Clastres (1978), é o instrumento de emissão de poder nas sociedades indígenas -, mas também de ações de ocupação de espaços geográficos e simbólicos que as sociedades indígenas vêm buscando fazer entender, ao Estado e aos não índios de modo geral, que não são apenas diferentes do "homem branco", mas diversas entre si: possuem línguas, modos de socialidade, conhecimentos cosmológicos, regimes políticos e econômicos distintos. E que essa diversidade não pode ser ignorada, nem subtraída.

Essa pletora de diversidades, testemunho de uma humanidade rica em sua heterogeneidade, entretanto, é tratada como se fora uma ofensa por aqueles que, com razão, os índios consideram seus inimigos. No discurso desses "inimigos dos índios”, as populações indígenas são vistas simplesmente como entraves ao desenvolvimento econômico.

Os tempos atuais são sombrios para quem não crê nesse desenvolvimento econômico, sustentado no "capital”, como panaceia sócio-político-econômica. Aqui, os índios parecem ter companhia. A ocupação do plenário da Câmara 
Federal, no "abril indígena" de 2013 , se não pode ser associada diretamente às mobilizações encabeçadas pelos jovens que eclodiriam em junho desse mesmo ano por todo o país, terminam por juntar-se a essas pelo sentido que carregam. Tais mobilizações, expressões de um movimento difuso, mostraram, entre outras coisas, uma insatisfação generalizada com a desigualdade social feroz de um país que faz da vida de uma grande maioria um grande sofrimento, reservando $\mathrm{o}$ mesmo tratamento injusto às minorias.

O que os índios e as mobilizações de junho parecem dizer conjuntamente, cada qual com sua própria agenda, é que se recusam a ser moídos pela engrenagem do sistema. Uma recusa que aponta como lugar privilegiado para o debate a esfera da política, mas não a política morna e de viés economicista do status quo. Algo diagnosticado por Werneck Vianna (2013) num artigo de jornal em relação às mobilizações de junho, quando diz que essas mostraram ser um movimento de retomada de uma ação política que havia sido abandonada após a constituinte de 1988 em favor das "artes calculadoras da economia". Numa análise mais aprofundada que avança em linha aparentada, Pignarre e Stengers (2007, p.27) apontam diretamente o capitalismo como aquilo que "nos afeta quando desprezamos a política: aquilo cujo próprio modo de funcionamento mata a política".

Dentro desse quadro maior do embate entre economia e política, as lutas indígenas são pelo reconhecimento e garantia de sua vida do modo diverso como se apresenta, os quais dependem fundamentalmente do direito à terra, tema que é o ponto fulcral em torno do qual se mobilizam as tensões voltadas aos índios. Na base dessas, o que há são modelos de relacionamento com os entes do planeta (fauna, flora, humanidade) radicalmente opostos entre si. É do enfrentamento político entre tais modelos que o artigo irá tratar, trazendo à luz a peleja dos índios com o agronegócio e seus representantes no Congresso Nacional, na qual o campo normativo surge como espaço privilegiado de disputa na caução de direitos. Por fim, para que se possa compreender as causas e efeitos dessa contenda, valer-nos-emos do caso dos Guarani e Kaiowá do Mato Grosso do Sul, no qual manifesta-se exemplarmente também o protagonismo político indígena.

\section{A batalha do Congresso}

A ocupação indígena do plenário da Câmara no dia 16 de abril de 2013 - início da semana de mobilizações políticas que reuniriam cerca de setecentos índios em eventos em torno do dia 19, "dia do índio" - já é um fato histórico. Índios de várias etnias, pelo ímpeto da entrada e pela figura inusitada naquele ambiente, puseram para correr amedrontados parlamentares presentes na casa. As imagens desse evento, para além do aspecto cômico que apresentam ao mostrar "brancos" engravatados fugindo de índios de torso seminu, merecem uma análise aguçada. Mas, para o assunto deste artigo, tomaremos apenas um de seus significados. A ocupação foi o ápice das ações do movimento indígena que, a 
despeito de sua heterogeneidade política e de associações, vem agindo para tornar visível a posição de sujeito dos índios na luta por suas terras. Desde a constituinte de 1988, essa luta tem tido como lugar estratégico o Congresso Nacional.

As terras indígenas fazem parte de um quadro mais amplo de disputas envolvendo a questão fundiária, que opõe, de um lado, não exatamente de maneira orgânica, o agronegócio, a mineração, as políticas de desenvolvimento econômico do Estado, gestores públicos ligados ao setor agrícola e mineral; e, de outro, populações indígenas, quilombolas, populações tradicionais (caboclos, ribeirinhos, seringueiros, castanheiros), ambientalistas, antropólogos e indigenistas com diversas formações e origens. No centro dessas disputas estão, principalmente, as categorias: "Terra Indígena” (TI), garantida constitucionalmente pelo artigo 231, que faculta aos índios a posse permanente e o usufruto exclusivo sobre as terras que tradicionalmente ocupam; e "Unidade de Conservação" (UC), instituída constitucionalmente pelo artigo 225 e regulamentada pela Lei n.9985/2000 com o objetivo de proteger e conservar os recursos naturais e a biodiversidade presentes em um espaço delimitado definido pelo Poder Público.

A queda de braço no Congresso entre essas posições antagônicas saiu das fronteiras dos conhecimentos e políticas especializadas de maneira mais estrondosa, em 2012, com a aprovação da lei do "Novo Código Florestal" (NCF) (Lei Ordinária n.12.651/2012), doravante NCF, que veio revogar a Lei n.4.771 de 1965. Dentre as alterações que introduziu, o NCF flexibilizou a legislação que regulamenta a conservação e o reflorestamento de "Áreas de Preservação Permanente" (APP), ou seja, áreas de florestas frágeis localizadas em regiões de risco, como as que compõem as nascentes e margens dos cursos d'água natural, manguezais, restingas e topos de morro; reduziu as áreas de "Reserva Legal" $(\mathrm{RL})$, i.e., de cobertura de vegetação nativa nos imóveis rurais; e anistiou as multas daqueles que desmataram APP e áreas de RL até 22 julho de 2008. O recado da lei é muito claro: desmatar é Legal.

O que embala e legitima essa premissa é o velho discurso do desenvolvimento econômico revestido de cara nova, pois não se pode mais assumir despudoradamente que a natureza é um empecilho a ser superado e tampouco ostentar um juízo que despreze a função social da terra. Corroboram isso os discursos de Valdir Colatto (PMDB/SC) (Câmara dos Deputados, 2012, 13.832), um dos mais ferrenhos apoiadores da abertura de áreas protegidas à produção agrária, e do notório defensor do setor rural, Ronaldo Caiado (DEM/GO) (Câmara dos Deputados, 2012, 13858, 13836), proferidos em plenário no dia da votação final do NCF.

No bojo da discussão do NCF revelou-se para o grande público a existência da denominada "bancada ruralista", uma bancada suprapartidária formada por grandes proprietários de terra e seus apoiadores (i. e., aqueles que, sem serem fazendeiros, sustentam a causa do "setor rural"), institucionalmente constituída em mais de uma "Frente Parlamentar da Agropecuária". Na atual legislatura, de 
acordo com levantamento do Diap, essa bancada conta com 158 parlamentares numa Câmara de 513 deputados, ou seja, cerca de $30 \%$ da casa, e dezoito senadores de um total de 81 . O fim comum de seus membros é, de acordo com o requerimento 631/2011 que cria a mais recente dessas Frentes, "estimular a ampliação de políticas públicas para o desenvolvimento do agronegócio nacional". Com um número considerável, essa bancada tem peso para pressionar a Presidência a cada vez que aparece uma votação importante para o governo, ameaçando votar contra ou obstruir a pauta até que suas demandas sejam atendidas (Diap, 2011). A bancada ruralista consegue ainda aglutinar em torno de si aliados fortes, sobretudo na arena dos partidos de centro-direita, assim alcançando mais de $50 \%$ em uma votação. Foi isso que se viu na aprovação do NCF.

O modo de operação da bancada ruralista em torno ao Projeto de Lei (PL) do NCF é o padrão de atuação das bancadas setorizadas. A estratégia consiste em apresentar uma proposição legislativa, pressionar para a criação da "Comissão Especial" na qual ela será discutida e, sobretudo, indicar o relator do relatório que será transformado em lei.

Institucionalmente, a composição das Comissões deve ser proporcional à representação dos partidos no Congresso. Entretanto, esse princípio vem sendo burlado pela divisão setorizada que, por ter seus membros espalhados em diferentes agremiações partidárias, consegue indicá-los simultaneamente como representantes de partidos diferentes. No fim das contas, no lugar de uma constituição pluripartidária o que se vê nas comissões (que interessam a segmentos setorizados) são composições que apontam para partidos únicos, como: o par-tido do setor rural, o do setor religioso, o do setor empresarial, o das mineradoras etc. Foi, por exemplo, essa a estratégia utilizada pela bancada evangélica para apossar-se da Comissão de Direitos Humanos e Minorias da Câmara (CDHM), quando logrou emplacar um pastor fundamentalista como seu presidente, em 2013.

Por serem realizadas dentro da legalidade institucional e normativa, essas estratégias são validadas. Ora, se as bancadas setorizadas são conhecidas e seus membros nominados, como prova a institucionalização das "Frentes", isso deveria reger os processos de ocupação de espaços dentro de um Congresso que visasse à distribuição proporcional e heterogênea de forças. Tal desequilíbrio entre representatividade e vontade popular expressou-se, por exemplo, na votação na Câmara (feita em dois turnos) dos relatórios do NCF. Enquanto o primeiro relatório, o do deputado Aldo Rebelo (PCdoB/SP), teve, a despeito da pressão das organizações ambientalistas, 410 votos a favor num quórum de 475 votantes. O segundo relatório, do deputado Paulo Piau (PMDB/MG), teve a seu favor quase metade dos votos que aprovaram o relatório anterior, 228. Pode-se aventar que, pelo menos uma parte dos votos contrários (184, ao todo) ao relatório final estava prestando contas ao eleitorado, pois, entre o primeiro e o segundo relatórios, a discussão transbordou os muros do Congresso. 
A despeito da ideia generalizada de que no Brasil as leis "não pegam", há cada vez mais uma percepção da legislação como instrumento estratégico. Não é à toa que se deram conta disso setores que costumam prescindir das leis em regimes de exceção, como o grande latifúndio e os empreendimentos econômicos de vulto (privados e públicos, embora no Brasil essa separação pareça muitas vezes ser indiferente). Sua movimentação se expressa na questão indígena a partir do assalto dirigido ao capítulo "Dos Índios", estabelecido na Constituição de 1988 e que é um marco fundamental, não só para os direitos indígenas, mas para uma concepção universal de direito. Nele está garantida a diversidade sócio-linguístico-cultural indígena, assim como o direito originário sobre as terras tradicionalmente ocupadas por esses, e, de maneira importante, o Estado se apresenta como o garantidor e guardião dessas terras.

Assim, no tocante às populações indígenas, atualmente, tramita no legislativo federal cerca de uma centena de proposições que dispõem de temas variados tais como: mineração; demarcação; educação escolar indígena; meio ambiente e recursos naturais; cultura; radiodifusão; normas penais; atenção à saúde; recursos genéticos; entre outros. Desse rol, a maioria visa fragilizar os direitos indígenas à posse e usufruto de suas terras. ${ }^{5} \mathrm{E}$, em sua quase totalidade, as tramitações não passam por consulta, descumprindo, desse modo, normas às quais o Brasil é signatário e que, por isso, têm status constitucional, como a Convenção 169 da OIT, que estabelece a consulta e participação adequada dos povos indígenas ou "tribais" (nessa categoria, no caso do Brasil, se incluem as populações quilombolas) sempre que houver medidas legislativas e administrativas que os afetem.

Além do legislativo, é importante apontar que o Executivo e o Judiciário contribuem com seu quinhão nas dificuldades impostas à garantia legal da terra aos índios. Se dão com uma mão, agindo na defesa dos interesses indígenas, via principalmente Funai e Ministério Público, também tiram com outra. E, quando agem desse modo, o fazem com grande potencial nocivo. Foi assim com o Decreto n.1775/1996, produzido pelo ministro da Justiça Nelson Jobim, que, ao estabelecer os mecanismos administrativos dos processos de demarcação de Terras Indígenas, incluiu a possibilidade do contraditório, permitindo a contestação das terras por não índios que se considerem atingidos, numa inversão do direito, pois se esse é originário, tudo o que vem depois é grilagem.

Foi precisamente por essa brecha que se deu o processo da Terra Indígena "Raposa Serra do Sol" - território localizado no nordeste de Roraima e que abriga as populações indígenas Macuxi, Ingarikó, Patamona, Taurepang e Wapixana - o qual se arrastou por anos, encerrando-se somente em julgamento no STF, em 2009. Esse processo retardou a demarcação, homologação e desentrusamento da Terra Indígena, agudizou a violência na região e ainda produziu mais uma embrulhada normativa pela adição, na sentença do STF, de dezenove ressalvas às demarcações das Terras Indígenas (STF, 2010, p.56-8), as quais “[...] pretensamente procuravam conciliar os interesses indígenas, a defesa nacional e 
a preservação do meio ambiente" (Yamada; Villares, 2010, p.147). O grande risco que representavam as ressalvas devia-se a potencialidade de virem a ser regras jurídicas instituídas e aplicáveis a outras Terras Indígenas ${ }^{6}$ caso lhes fosse dado o valor de "força vinculante" quando do processo transitado em julgado, ou seja, dado por finalizado.

$\mathrm{O}$ mais recente atropelo aos direitos indígenas (assim como aos direitos legais, de modo geral), a edição da Portaria n.303/2012 pela Advocacia Geral da União (AGU), valeu-se desse ardil. Por meio das dezenove condicionantes impostas pelo STF para o caso específico da TI Raposa Serra do Sol, a Portaria dispôs sobre as salvaguardas a todas as Terras Indígenas, porém, não em favor do interesse indígena. O teor geral das ressalvas é o de uma ingerência absoluta do Estado sobre os territórios indígenas, o que vai de encontro não somente à Constituição, como aos acordos internacionais firmados pelo país, veja-se a já mencionada Convenção 169.7 A título de ilustração, basta saber que em nome dos interesses da política de defesa estratégica e da economia nacional podem-se instalar equipamentos militares, abrir estradas, impedir ampliação de Terras Indígenas já demarcadas sem considerar o processo histórico das demarcações, explorar recursos naturais sem consulta às comunidades indígenas envolvidas ou à Funai, entre outras intervenções. Esse gênero de intrusão já vem se dando, na prática, ao arrepio da lei, vide a instalação do complexo hidrelétrico de Belo Monte e a já antiga exploração da mineração por meio de garimpos em Terras Indígenas (Capiberibe; Bonilla, 2012). O principal objetivo da Portaria é, portanto, tornar de direito aquilo que é de fato.

Dalmo Dallari (2012) esclarece um dos porquês de a Portaria configurar um atentado à Constituição e à ordem legal. De acordo com o jurista, uma Portaria é um ato administrativo cuja ação restringe-se aos subordinados da autarquia que a expediu, portanto não tem força de lei (e muito menos de jurisprudência), não podendo determinar mudança em assunto constitucionalmente instituído.

Mas a principal contestação jurídica à Portaria é o fato de, no momento de sua publicação, o processo do STF ao qual se vincula, ou seja, a Petição 3.388 RR, ainda não haver transitado em julgado, aguardando decisão sobre os embargos declaratórios, ou seja, a explicação de partes da sentença apontadas como obscuras, omissas ou contraditórias pelos litigantes (Barroso 2013b, p.4). Em outras palavras, não é possível normatizar sobre solo não pavimentado. Por esse fato, o advogado-geral da União, ministro Luís Inácio Lucena Adams, viu-se obrigado a suspender a Portaria até o julgamento dos embargos.

Em outubro de 2013, o STF finalmente decidiu sobre os embargos de declaração do processo "Raposa Serra do Sol”, estabelecendo, entre outras coisas, que a sentença desse processo só incide sobre o caso que a suscitou (STF, 2013). Contudo, a insegurança jurídica instalada pelas condicionantes parece ainda não ter acabado, pois logo após o julgamento, o ministro Lucena Adams 
manifestou-se nos meios de comunicação afirmando que a Advocacia-Geral da União reeditaria a Portaria. Sua alegação é a de que se a sentença não prevê efeito vinculante, ela produz precedente jurisprudencial, o qual estaria posto nas conclusões do relatório do ministro Luís Roberto Barroso votado e aprovado pelo pleno, mais exatamente, na parte inicial (grifada) da seguinte asserção: “[...] $A$ decisão proferida na Pet 3.388/RR tem a força intelectual e persuasiva de uma decisão do Supremo Tribunal Federal, mas não é vinculante, em sentido técnico, para juízes e tribunais, quando do exame de outros processos, relativos a terras indígenas diversas [...]" (Barroso, 2013b, p.40 - grifo nosso). Como se vê, o advogado-geral da União ignora de maneira expressa o restante da sentença, aquele que justamente faz que a Portaria n.303 perca seu argumento legal.

O caso Raposa Serra do Sol foi um dos mais ruidosos a tramitar no Supremo, mas não é filho único. Hoje há mais de 150 ações contestando demarcações de Terras Indígenas na mais alta corte do país (Yamada; Villares, 2010, p.61). A advogada Erika M. Yamada informa ainda que só na seção de Cuiabá da Justiça Federal do Mato Grosso, até 2010, havia 120 processos em curso sobre o tema, alguns iniciados desde os anos 1980 (ibidem), e aponta o uso cada vez mais frequente de liminares judiciais, ou seja medidas judiciais provisórias interpostas antes de o processo ser instaurado, que perduram por décadas, imobilizando a marcha administrativa necessária para que as demarcações transcorram (ibidem). Esse é o efeito da judicialização dos processos envolvendo demarcação. Se a Terra Indígena demarcada é um direito constitucional fundamental e garantido é de perguntar, portanto, qual o significado do termo "justiça” para os tribunais que enredam esse direito no emaranhado de seu sistema burocrático.

\section{Os aliados}

Mas nem tudo é desgraça, os povos indígenas não estão sós no Congresso, embora sua base de apoio seja bastante restrita. Desde 2011, existe uma "Frente Parlamentar de Apoio aos Povos Indígenas", criada pelo requerimento (2893/2011) apresentado pelo deputado Padre Ton (PT/RO) com a assinatura de 187 deputados e deputadas. No entanto, contam-se nos dedos das mãos os verdadeiros aliados dos índios.

Uma das consequências da ocupação do abril indígena, ou seja, da ação direta dos índios, foi a de ativar e reunir essa pequena Frente em um grupo estruturado em torno a uma agenda legislativa de ações em defesa dos povos indígenas (Câmara dos Deputados, 2013b). Começou-se por incluir representantes dos índios no Grupo de Trabalho "Questão das Terras Indígenas” criado dentro da Comissão de Legislação Participativa da Câmara dos Deputados como resposta da mesa da Câmara à pressão produzida pela ocupação indígena. Esse GT é composto por representantes das populações indígenas, por representantes da Frente de Apoio aos Povos Indígenas e da bancada ruralista.

Alguns deputados, membros desse GT, também entraram com um Mandado de Segurança (MS-32262) no Supremo Tribunal Federal (STF) contra a 
mesa da Câmara solicitando a suspenção da tramitação do PEC n.215/2000 ${ }^{8}$ e a exclusão de sua deliberação na casa, assim como de todos os onze projetos a ele apensados, por inconstitucionalidade. Embora o ministro relator Luís Roberto Barroso (2013a, s. p.) não tenha concedido a liminar solicitada, alegando a necessidade de as Casas Legislativas "amadurecerem o debate público" sobre o tema, em seu parecer, explicita que o direito indígena à terra não é um direito de propriedade ou posse, mas de "índole e estatura constitucional" fundamental para a manutenção e proteção da "cultura dos povos indígenas", aspecto que explicita seu caráter de cláusula pétrea, diz o ministro: "Como a cultura integra a personalidade humana e suas múltiplas manifestações compõem o patrimônio nacional dos brasileiros (CF/88, art.215 e 216), parece plenamente justificada a inclusão do direito dos índios à terra entre os direitos fundamentais tutelados pelo art. 60, $\mathfrak{S} 4^{\circ}, \mathrm{IV}$, da Constituição" (Barroso, 2013a, s. p.). Além disso, o ministro também sublinhou que o rito demarcatório é tarefa exclusiva do executivo, pois, do contrário, os direitos das minorias estariam sujeitos às "maiorias de ocasião" (ibidem). Ambas asserções são importantes, porque reforçam a jurisprudência sobre o tema estabelecida na Carta Magna.

A ação mais recente da Frente de Apoio às Populações Indígenas é o requerimento 82/2013, proposto pela deputada Janete Capiberibe (PSB/AP), que inclui os índios na Comissão de Legislação Participativa, na condição de convidados, para debater as proposições que os afetem direta ou indiretamente. É um meio de, enfim, cumprir-se, ainda que minimamente, a exigência constitucional e normativa de consulta e participação das populações afetadas pelas ações do legislativo.

Da agenda pró-indígena no Congresso, destaca-se o "Novo Estatuto do Índio" (PL n.2057/1991), proposto em 1991 pelo então deputado Aloizio Mercadante (PT/SP). Essa é a lei fundamental para resguardar os direitos dos índios em sua integridade, porquanto regula a situação jurídica indígena nos âmbitos da pessoa, das comunidades e das organizações e reforça o que já está posto na Constituição. O PL, que é respaldado pelas organizações indígenas, encontra-se pronto para a votação em plenário, mas, como se diz no jargão jurídico, a mesa da Câmara está "sentada sobre o processo" há décadas.

Outro projeto importante é o PL n.3571/2008 que cria o Conselho Nacional de Política Indigenista (CNPI), um órgão com função deliberativa - que visa substituir a atual "Comissão Nacional de Política Indigenista", instituição de caráter consultivo -, que irá atuar em relação às diretrizes da política nacional indigenista e será composto paritariamente por representantes do Executivo, dos Povos e organizações indígenas de todas as regiões brasileiras e de entidades indigenistas. Nesse momento, o projeto tramita na "Comissão da Amazônia", rebatizada de Comissão de Integração Nacional, Desenvolvimento Regional e da Amazônia (Cindra). Essa comissão é dominada por membros da bancada ruralista, responsáveis por fazer a troca simbólica de seu nome. Portanto, não é de 
admirar que o relator do PL da CNPI seja um membro dessa bancada, deputado Jerônimo Goergen (PP/RS), tampouco surpreende seu relatório pela rejeição do PL, alegando que a política indigenista do Estado, que envolve, entre outras coisas, a deliberação sobre questões fundiárias, não pode ficar nas mãos de um Conselho que "[...] sofrerá uma forte influência das organizações não governamentais nacionais e estrangeiras vinculadas à defesa dos interesses indígenas. [...]" (Câmara de Deputados, 2013a, p.6). Não por acaso, esse deputado é um dos autores do Requerimento de Instituição da CPI (RCP-22/2013) para investigar a atuação da Funai e do Incra na demarcação de Terras Indígenas e de remanescentes de quilombos.

A CPI da Funai e do Incra (RCP - 22/2013) é parte da campanha feita pelos ruralistas para mudar o rito demarcatório, buscando desqualificar o processo administrativo. Essa campanha tem nos laudos antropológicos realizados pela Funai seu alvo preferencial. ${ }^{9}$ Para tanto, os ruralistas pressionam o governo, ao mesmo tempo que acionam seus aliados dentro dele. Foi desse modo que, em maio de 2013, lograram obter uma declaração da ministra chefe da Casa Civil da Presidência da República, Gleisi Hoffmann, pela qual a Embrapa, o Ministério da Agricultura, Pecuária e Abastecimento, o Ministério do Desenvolvimento Agrário passariam a avaliar os estudos antropológicos realizados pela Funai. Contudo, essa proposta não progrediu, foi enfraquecida por um posicionamento da Embrapa julgando-se incapaz de interferir no sistema de demarcação e também por uma forte reação da sociedade. ${ }^{10}$

Em suma, todo esse litígio que se dá no âmbito normativo e judiciário descreve uma disputa entre modelos de exploração de recursos naturais (e de entendimento do que é fundamental à vida) absolutamente distintos. $\mathrm{O}$ butim dessa queda de braço é o espaço territorial brasileiro.

Se contarmos que as Terras Indígenas e as Unidades de Conservação que hoje contêm 170 milhões de hectares dos 537 Mha de vegetação natural existentes no país (Sparovek et al., 2010) - são, por vezes, as únicas extensões de biodiversidade em pé em alguns espaços geográficos, sua preservação obviamente não diz respeito somente aos povos indígenas.

\section{O agronegócio}

O agronegócio, representado pela bancada ruralista, é mais do que uma simples opção produtiva, é um modelo de sociedade. Seus impactos afetam não só aqueles que estão diretamente envolvidos com ele (que vivem e/ou trabalham à proximidade ou em suas lavouras, pastagens e indústrias), mas todos os cidadãos que consomem seus produtos. E tais impactos não podem ser considerados como meros "efeitos colaterais", mazelas necessárias de um sistema produtivo que garante a condição brasileira de "celeiro do mundo", mas sim como condições de sua própria reprodução.

Os fatos mostram que os processos do agronegócio não são sustentáveis. Assim, quando uma terra não produz mais, um grão não resiste a determinadas 
condições climáticas ou sofre da ação de alguma praga natural, novos aditivos químicos devem ser introduzidos ou novas espécies transgênicas produzidas que eliminam espécies naturais, além daquelas supostamente visadas, provocando novos efeitos sobre a biodiversidade, e assim por diante.

Os principais cultivos desse negócio são a soja, o milho e a cana-de-açúcar, voltados à produção de biocombustíveis, de alimentos (principalmente rações) e a criação extensiva de gado de abate, visando a exportação. Segundo um estudo do Fórum Mato-Grossense de Meio Ambiente e Desenvolvimento, o "celeiro do mundo" não produz alimentos para a população da região, já que o estado do Mato Grosso importa 90\% dos hortifrutigrangeiros de São Paulo e do Paraná, necessitando um imenso aporte de combustível para alimentar a população (Schlesinger, 2013). O mesmo estudo aponta também os problemas socioambientais desse tipo de economia que, fundamentando-se na concentração da propriedade fundiária e na monocultura, requer grandes extensões de terra para se desenvolver. Para tanto, expele pequenos produtores e comunidades tradicionais de suas proximidades e, com sua mecanização acentuada, provoca desemprego e êxodo rural. O fato de o país priorizar a produção para atingir superávit de balança comercial, em detrimento do consumo interno, também exerce forte pressão nos preços dos alimentos, o que levou alguns especialistas a culpar recentemente o agronegócio pela alta da inflação. ${ }^{11}$

Quanto aos problemas ambientais e de saúde pública que o modelo carrega, vão da poluição dos lençóis freáticos, passando pela intoxicação dos trabalhadores por agrotóxicos, até a emissão de gazes de efeito estufa, grandes responsáveis pelo aquecimento global (Pignati, 2007, p.81-105).

A produção de cana-de-açúcar é a terceira maior consumidora de agrotóxicos após a do milho e a da soja. A queima de seus resíduos é tida como responsável por $98 \%$ das emissões de gazes de efeito estufa do país. Sem contar que a cana é uma voraz consumidora de água, atingindo, para a produção de uma safra nacional, um uso que poderia abastecer dezoito milhões de pessoas durante um ano (ibidem).

Outro grande problema atrelado a esse modelo é o desmatamento, tema no cerne das discussões no Congresso Nacional. O ciclo do desmatamento para fins agrícolas começa com a expulsão das populações tradicionais, prossegue com a retirada e a venda da madeira da área desocupada e se conclui com as queimadas para abrir pastagens para o gado. De cinco a dez anos, a terra das pastagens esgota-se, abrindo então caminho para a soja e demais commodities. $\mathrm{O}$ Mato Grosso é um caso "exemplar". Nos últimos dez anos, o estado se tornou o maior produtor de soja do país, o preço foi pago por um de seus biomas, o cerrado, que já perdeu $45 \%$ de sua cobertura original (Sakamoto, 2010).

Em suma, o agronegócio é um modelo que necessita sempre mais: mais terras, mais água, mais agrotóxico, mais transgênicos. Nos últimos trinta anos, o centro-oeste, região que concentra a produção agropastoril, vem sendo con- 
sumido pelo desmatamento, que penetra agora com força na região amazônica, avançando para o Acre e o sul do Amazonas, onde o desmatamento já atinge terras indígenas como a dos isolados Katauixi (Terra Indígena Katauixi/Jacaréuba) e a Terra Indígena Caititu, dos índios Apurinã. Consequentemente, os casos de conflitos agrários nessa região explodiram, registrando dezenas de assassinatos de camponeses, assentados, seringueiros e índios na última década - só em 2012, foram registrados cinco assassinatos nas regiões norte de Rondônia e sul do Amazonas (CPT Nacional, 2012, p. 108; 113-14).

Lévi-Strauss (2009, s. p.), em um artigo escrito no começo dos anos 1990 que teve como mote a doença da vaca louca, faz uma premonição terrível, dizendo:

num mundo em que a população global provavelmente terá dobrado em menos de um século, o gado e outros animais de criação se tornarão temíveis concorrentes do homem. Calcula-se que nos Estados Unidos dois terços da produção de cereais se destinam a alimentá-los. E não nos esqueçamos de que esses animais, em forma de carne, nos fornecem um número de calorias bem inferior àquele que consumiram no curso de suas vidas $[\ldots]$.

Quando se fala em modelos de desenvolvimento, está se falando dessa inviabilidade apontada por Lévi-Strauss que, lembremos, se apresenta no próprio sistema do agronegócio.

\section{O caso Guarani e Kaiowá}

A história dos Guarani e Kaiowá do Mato Grosso do Sul, sem ser única dentre as histórias do contato entre índios e não índios no Brasil, é bastante ilustrativa dos motivos por que brigam os povos indígenas e o agronegócio. Por outro lado, essa história também ajuda a compreender o movimento atual pelo qual as populações indígenas tomam a frente de suas lutas, por meio de atos políticos, cujo intuito é explicitamente o de se pôr como sujeitos plenos de suas ações.

O estado de Mato Grosso do Sul abriga uma das maiores populações indígenas do Brasil. Estima-se que haja cerca de sessenta mil indígenas no estado, e aproximadamente 45 mil são Kaiowá e Guarani. ${ }^{12}$ Esses povos concentram-se hoje na região sul do estado, cuja base econômica se assenta no agronegócio. Sua história é marcada pela perda brutal de condições essenciais de vida: expropriação de suas terras, contaminação das águas e do ar, confinamento em reservas e espaços minúsculos etc. No entanto, resistem. Sua resistência fundamenta-se na luta pela terra e na perpetuação da língua guarani, ambas garantias absolutas de sua continuidade física e cultural.

Habitantes imemoriais da região da atual tríplice fronteira (Brasil - Paraguai - Argentina), foram alvo, desde o século XVII, de diversas tentativas de redução pelos jesuítas, mas o modelo das missões não prosperou, e os índios, então conhecidos como Itatim, levaram uma vida relativamente tranquila até a Guerra do Paraguai (1864-1870). Após a guerra, o governo brasileiro decidiu 
povoar com população não indígena a região considerada então como um amplo "espaço vazio". Foi nessa época que a Companhia Mate Laranjeira se instalou na região e, por mais de um século, manteve contratos de arrendamento público de terras, ocupando praticamente toda a região austral do atual Mato Grosso do Sul.

A partir do final do século XIX, chegou a vez das frentes agropastoris e suas fazendas avançarem para os campos dos atuais municípios de Amambaí, Ponta Porã e Bela Vista. Mas foi na década de 1940 que se iniciou o processo de expropriação que levaria à atual situação das populações indígenas no Mato Grosso do Sul. O governo Getulio Vargas passou a considerar toda a região como formada por "terras devolutas" e a vender estas últimas a colonos, criando as Colônias Agrícolas Nacionais. Como se pode imaginar, essa instalação em terras tradicionalmente ocupadas pelos Kaiowá e Guarani acarretou o deslocamento de aldeias inteiras para outras áreas.

Nos anos 1950, o processo se acelerou, ampliando o problema do desmatamento na região. O Serviço de Proteção ao Índio (SPI) criou então oito reservas de terras demarcadas (Dourados, Caarapó, Amambaí, Piraju'i, Jakareí, Takuapiry e Sassoró) para confinar os indígenas da região, "liberando" assim as terras para a frente de expansão econômica. Essas reservas concentram hoje a maior parte da população Kaiowá e Guarani da região. Nesse processo, os Guarani e Kaiowá também se tornaram um importante contingente de mão de obra, muitas vezes trabalhando em fazendas situadas em suas antigas terras tradicionais.

Na década de 1970, a soja foi introduzida na região, associada à ampla mecanização das atividades agrícolas e exigindo a consequente ampliação dos espaços cultiváveis e o desmatamento das áreas ainda preservadas. Essas áreas coincidiam em grande parte com as aldeias de "fundos de fazenda", espaços situados em terras já tomadas por fazendeiros, mas onde os Guarani e Kaiowá resistiam e encontravam melhores condições de vida do que nas reservas.

Em 1978, ocorre um evento que irá definir a reocupação e os acampamentos como uma estratégia de retomada de terras. Naquele ano, um grupo de índios Kaiowá e Guarani que havia sido expulso de uma área tradicional situada nas terras da Cia. Mate Laranjeira - e confinado em uma reserva resolve voltar para sua terra e reivindicar a área. Inicia-se então o longo processo de "retomada" das terras Guarani e Kaiowá, que, como mostra Pimentel (no prelo), vai consolidar o protagonismo Kaiowá e Guarani. Hoje, contam-se dezenas de acampamentos indígenas espalhados na beira das estradas, com centenas de pessoas aguardando a oportunidade de retornar às suas terras.

As condições de vida confinada nas reservas, nas minúsculas terras demarcadas e nos acampamentos são marcadas por muitos problemas, como a desnutrição crônica, por exemplo. ${ }^{13}$ Há altíssimas taxas de suicídio, dezenove vezes superiores à taxa nacional, atingindo principalmente adolescentes indígenas. Se- 
gundo números da Secretaria de Saúde Indígena do Ministério da Saúde (Sesai), em 2012, foram 56 suicídios Guarani e Kaiowá. Entre 2000 e 2011, totalizam-se 555 suicídios, constituindo o que o Conselho Indigenista Missionário (CIMI) chama de "genocídio silencioso". Além disso, a violência nas reservas é também elevada, envolvendo alcoolismo, uso de drogas, discriminações, violência físicas, sem esquecer os atropelamentos (que afetam principalmente os acampados na beira das estradas) (CIMI, 2012).

No universo das violências a que estão submetidos os índios do Mato Grosso do Sul é estarrecedor o número de assassinatos de lideranças, rezadores e representantes indígenas ocorridos nos últimos anos. Aí incluídos os mais recentes do cacique Nísio Gomes, em 2011, e do jovem Oziel Terena, em abril de 2013. Segundo dados do Relatório sobre violências contra os Povos Indígenas (CIMI, 2012), o Mato Grosso do Sul é o estado onde mais se assassinam índios: em 2012, foram sessenta assassinatos de indígenas no Brasil, dos quais 37 no Mato Grosso do Sul. Desses 37 mortos, 34 eram Guarani e Kaiowá, dois Terena e um Ñandeva. Entre os anos 2001 e 2012, só nesse estado foram assassinados 372 indígenas.

Há quatro anos, essa situação levou o Ministério Público Federal à região, e foi elaborado um Termo de Ajustamento de Conduta (TAC) assinado pela Funai em nome do governo federal, assumindo o compromisso de identificar um total de 36 novas terras indígenas. Ao fazer isso o governo manifesta que o problema social que afeta os Guarani e Kaiowá é um problema fundiário. No entanto, os fazendeiros e o establishment local insistem em refutar essas reivindicações, alegando que o fundamental seria intensificar a presença do Estado (através das políticas públicas) nas terras indígenas já existentes. ${ }^{14}$ As reocupações indígenas os incomodam, testemunha disso é o recente projeto de lei (PLS n.349/2013), apresentado pela senadora Kátia Abreu (PSD/TO) que pretende criminalizar essas reocupações, punindo os invasores com o adiamento de demarcações (cf. quadro em Capiberibe; Bonilla, 2013).

\section{Rompendo a invisibilidade}

O contexto sul-mato-grossense ilustra em fatos e números a guerra que os índios estão vivendo e prenuncia os desafios que eles enfrentarão no futuro. Se um "outro mundo é possível" nos termos usados em Seattle e retomados por Pignarre e Stengers (2007), o caminho desse mundo deve romper com as "alternativas infernais", com os argumentos circulares dos "efeitos colaterais", dos "maus necessários" e dos "não temos escolha" do capitalismo. Também vale mencionar aqui um dos argumentos desenvolvidos por Stengers quando denuncia o "refrão obsceno" dos especialistas que opõe o argumento da "prova" a qualquer questão, objeção, proposta inovadora que possa vir a incomodar o que já está estabelecido. Assim, o primeiro papel do refrão do "não está provado, não está provado!" dos especialistas e cientistas é justamente de "calar, de separar o que será considerado objetivo ou racional, do que será rejeitado como subjetivo 
ou ilusório, ou oriundo de qualquer manifestação de vínculos irracionais a modos de vida infelizmente condenados-pelo-progresso" (Stengers, 2009, p.86).

Como mostra Manuela Carneiro da Cunha (2009), as populações indígenas e tradicionais são "cruciais" para a conservação da biodiversidade, há tempos que os índios demonstram que conhecem ao menos alguns dos possíveis caminhos onde diversidade e bem viver podem simplesmente conviver.

As ocupações indígenas de terras, gabinetes públicos, rodovias, canteiros de obras e do próprio Congresso Nacional são meios de tentar romper a invisibilidade e a surdez que os cerca e cerceia sua voz. Se conseguirmos vê-los e ouvi-los, talvez sejamos capazes, como propõe Stengers (2009, p.17-18), de "criar uma vida que explore conexões com novas potências de ação, de sentimento, de imaginação e pensamento [...] forçando-nos assim a pensar no que seria necessário para possibilitar um futuro que escape à destruição e à barbárie".

$\mathrm{Na}$ correlação de forças em torno da disputa pelos recursos naturais, os povos indígenas encontram-se em franca desvantagem. Está claro que não contam com o apoio incondicional de nenhuma das pontas que formam o Estado. A impunidade que acoberta os assassinos e mandantes das mortes indígenas significa a manutenção desse estado precário de direitos.

Por isso, o protagonismo indígena vem optando por uma estratégia de “des-invisibilização", valendo-se da dinâmica das ocupações e da apropriação das novas tecnologias. Como ocorreu em outubro de 2012, quando, após receberem uma liminar lhes negando o direito a permanecer em suas terras, os Guarani de Pyelito Kue divulgaram uma carta na qual se dispunham a morrer mas não a sair de suas terras. Esse fato foi amplamente divulgado, gerando uma grande mobilização na internet, que levou milhares de pessoas a escolherem seu lado, divulgando a hashtag "\#somos todos Guarani-Kaiowá” ou acrescentando o sobrenome Guarani-Kaiowá a seus nomes nos perfis das principais redes sociais. Em setembro de 2013, anunciando a semana nacional de mobilização indígena, os Guarani Mbya de São Paulo bloquearam a Rodovia dos Bandeirantes - que atravessa suas terras - exigindo o reconhecimento dessas e a suspensão da PEC 215 (e dos demais projetos revisionistas). Simultaneamente, divulgaram na internet um vídeo com falas de crianças e jovens da aldeia, do qual destacamos a seguinte: “Nós fizemos isso, para vocês, brancos, saberem que nós existimos!". 15

Essa invisibilidade decorre, a nosso ver, do que Bruno Latour (2001) chamou de a "paz dos modernos", uma paz estabelecida por um mundo baseado na razão e na ciência (seja ela biológica ou econômica) e sustentada pela tolerância aos Outros (os irracionais, os selvagens, os primitivos, as minorias, os pobres etc.), que se apresenta em grandes discursos pacificadores e universalistas sobre direitos humanos e de pertencimento a um mundo comum. Seria bom não fosse o fato de que o mundo universal e tolerante dos modernos é um mundo concebido à sua própria imagem, sendo assim, se aceita a existência do Outro é somente na condição de englobá-lo em sua própria elaboração do que é o mundo. 
No dia 28 de maio desse ano, o representante dos Guarani e Kaiowá, Elpídio Pires, disse perante vários membros da Aty Guasu, Assembleia Geral dos Guarani e Kaiowá, e Marcelo Zelic, assessor da Comissão Nacional da Verdade:

Índio não entende papel, essas leis nos levarão até não sei quando para dar nossa terra, eu estou agora em meio hectare e tenho três mil hectares ainda para conviver com a minha comunidade, a lei existe, mas os caras que trabalham em cima da lei não estão fazendo, por isso o índio fala que pra nós é só papel, eu vou é tomar minha terra, vocês é que vão se virar com a lei de vocês, a lei pode levar tantos mil anos, mas para o índio, agora é o momento.

Invadindo, ocupando e procurando se “des-invisibilizar", os índios estão justamente dizendo não ao mundo da "tolerância". É preciso dar nomes aos bois, nomear o inimigo e por sua vez ser reconhecido como tal, como inimigo do inimigo. A indiferença dos governos às questões indígenas é uma indiferença “moderna”, ou seja, "não reconhece a existência de conflitos possíveis, mas só de representações superficiais, que só podem remeter a um mesmo mundo conhecido racionalmente" (o nosso) (Latour, 2001, p.7). O grito dos índios pede que sua posição de sujeitos plenos seja enunciada, que lhes seja reconhecida sua dignidade para poder guerrear, enfrentar seu inimigo. Parafraseando Latour, quer se trate de fazer diversidade ou uniformidade, que apareçam finalmente as forças em jogo, os oponentes, os fronts, as contradições violentas.

\section{Notas}

l Gostaríamos de agradecer a leitura atenta do(a) parecerista cujas recomendações foram aqui em grande parte adotadas. Informamos ainda que uma versão resumida e modificada do presente texto foi publicada na revista Les Temps Modernes (Bonilla; Capiberibe, 2014).

2 Como aponta Carneiro da Cunha (1992, p.133), se nos três primeiros séculos da colonização a questão indígena que suscitava legislação e execução política foi uma questão econômica de acesso à mão de obra, do século XIX aos nossos dias, passou a ser essencialmente uma questão de terras. Para uma leitura da legislação indigenista dos séculos XVI ao XVIII, ver Perrone-Moisés (1992), e para um entendimento da história de aprisionamento e escravização da mão de obra indígena em razão da economia da São Paulo, desse mesmo período, ver Monteiro (1994); por fim, para a política indigenista estabelecida no século XX e o lugar do índio na sociedade nacional, ver Lima (1992).

3 Uma medida do que estamos chamando de "criatividade" pode ser entrevista nos depoimentos indígenas reunidos na edição 1996-2000 do livro Povos indígenas no Brasil (VV, AA, 2000), nos quais sobressai o caráter deletério do encontro com os "brancos" (Viveiros de Castro, 2000).

4 As falas desses três atores vem aparecendo, há um certo tempo, com destaque em diferentes veículos de comunicação nacional e internacional analisando questões que tocam diretamente suas populações de origem, como o caso da UHE de Belo Monte que atinge diversas populações que habitam o entorno da bacia do rio Xingu, entre 
elas os Kayapó; e questões de ordem mais geral, com as que tocam à fragilização da figura jurídica Terra Indígena. Davi Kopenawa é também autor do livro La chute du ciel (Kopenawa; Albert, 2010), escrito em diálogo com o antropólogo Bruce Albert, cujo objetivo político direto é o de ensinar ao "povo da mercadoria" as consequências cósmicas do desmatamento, da poluição dos rios, do ataque às florestas e aos povos que as habitam.

5 Para um quadro extenso e explicativo, porém ainda não exaustivo, das proposições legais do legislativo e do executivo que incidem sobre Terras Indígenas ver Capiberibe e Bonilla (2013). Esse quadro apresenta a variedade nos gêneros de proposição direcionadas às Terras Indígenas - PL (Projeto de Lei), PEC (Projeto de Emenda à Constituição), PDC (Projeto de Decreto Legislativo), PLP (Projeto de Lei Complementar), Decretos-Lei e Portarias. Essa estratégia conduz à reduplicação de proposições cuja função parece ser a de exercer função permanente sobre esse tema. O quadro também apresenta as autorias dos projetos dando nomes, partidos e localizações geográficas, as quais apontam principalmente para os estados do front do agronegócio.

6 Para uma problematização do caráter de legislação positiva embutido nessa sentença do STF, ver Yamada e Villares (2010).

7 Em Yamada e Villares (2010) há uma reflexão mais detalhada sobre o aviltamento legislativo que as condicionantes da Petição 3.388-RR representam.

8 A PEC 215 é um projeto de emenda à Constituição de autoria do deputado Almir Morais Sá (PPB/RR) que altera os artigos 49, 225 e 231 da Constituição Federal, incluindo entre as competências exclusivas do Congresso Nacional a aprovação de demarcação das Terras Indígenas e a ratificação das demarcações já homologadas. Os projetos a ele apensados são: PEC 257/2004, PEC 275/2004, PEC 319/2004, PEC 156/2003, PEC $37 / 2007$, PEC $117 / 2007$, PEC 411/2009, PEC 415/2009, PEC 161/2007, PEC 291/2008, PEC 291/2008.

9 O laudo antropológico é instrumento de instrução primeira e primordial no processo de demarcação, pois é por meio dele que se fundamenta a demarcação da terra, portanto, fragilizá-lo interessa aos defensores do grande latifúndio. O teor da desqualificação pode ser divisado no discurso proferido em plenário pelo deputado ruralista Alceu Moreira (PMDB/RS), no dia 20.11.2013, no qual vilipendia o ofício do antropólogo e o instrumento do laudo técnico antropológico, disse ele: "O laudo é feito no silêncio, só a Funai e o vigarista de encomenda é que fazem o laudo antropológico. Às vezes eles levam anos: eles têm que justificar teórica e tecnicamente a mentira; eles criam sítios arqueológicos; eles enterram e desenterram objetos; eles fazem toda gatimonha para parecer uma coisa legítima. Nasce, então, o laudo antropológico" (Câmara dos Deputados, 2013b, s. p.).

10 Veja-se a carta endereçada à presidenta Dilma Rousseff por juristas, antropólogos, defensores de direitos humanos, entre outros. Disponível em: <http://revistaforum. com.br/blog/2013/06/juristas-e-intelectuais-questionam-dilma-sobre-questao-indigena/>. Acesso em: 24 set. 2013.

11 Ver as colocações da Associação Brasileira de Reforma Agrária (Abra) sobre isso: disponível em: <http://www.mst.org.br/A-inflacao-dos-alimentos-se-deve-a-politica-agricola-adota-pelo-governo-afirmam-especialistas>. Assim como o artigo de Amy Horton sobre a relação entre agronegócio e crise alimentar: disponível em: <http://www. theguardian.com/global-development/poverty-matters/2012/aug/02/world-teetering-brink-global-food-crisis $>$. 
12 Os dados apresentados a seguir sobre a história e a situação dos povos Guarani e Kaiowá encontram-se em: Grunberg e Melià (2008); Thomaz de Almeida (1984). Sobre a gênese do movimento de retomada de terras e a situação atual, ver: Pereira (2012a e 2012b); Pimentel (2012); e Pimentel e Moncau (2012).

13 Disponível em: <http://pib.socioambiental.org/es/noticias?id=14992>. Acesso em: 25 set. 2013.

14 Sobre a oposição entre políticas públicas e demarcações no Mato Grosso do Sul, ver o artigo recente de Pimentel (no prelo).

15 Disponível em: <http://www.youtube.com/watch?v=eV7WMdvGirM>. Acesso em: 26 set. 2013.

\section{Referências}

BARROSO, L. R. Medida cautelar em mandado de segurança MS 32262 MC -DF: decisão monocrática, relator min. Luís Roberto Barroso. 2013a. Disponível em: <http:// www.stf.jus.br/portal/jurisprudencia/listarJurisprudencia.asp?s l = $\% 28 \mathrm{MS} \% 24$. SCLA.+E+32262.NUME.\%29\&base=baseMonocraticas\&url=http://tinyurl.com/ $\operatorname{lm} 7 \mathrm{zjzv}>$. Acesso em: 25 set. 2013.

Embargos de declaração na petição 3.388 - RR: relatório do min. Luís R. Barroso. 2013b. Disponível em: <http://www.conjur.com.br/dl/decisao-barroso-raposa-serra-sol.pdf>. Acesso em: 20 nov. 2013.

BONILLA, O.; CAPIBERIBE, A. L'invasion du Congrès: contre qui luttent les Indiens. Les Temps Modernes, ano 69, n.678, p.108-21, abr.-maio-jun. 2014.

CÂMARA DOS DEPUTADOS. Diário da Câmara dos Deputados, Brasília-DF, ano LXVII, n.064 (quinta-feira, 26 de abril de 2012). Disponível em: <http://imagem.camara.gov.br/Imagem/d/pdf/DCD26ABR2012.pdf\#page=195>. Acesso em: 13 set. 2013.

Relatório projeto de lei 3571, de 2008 - Dep. Jerônimo Goergen. 2013a. Disponível em: <http://www.camara.gov.br/proposicoesWeb/prop_mostrarintegra?codteor =1171719\&filename=Tramitacao-PL+3571/2008>. Acesso em: 20 nov. 2013.

Agenda Legislativa da Frente Parlamentar de Apoio aos Povos Indigenas. 2013b. Disponível em: <http://www.ecoamazonia.org.br/wp-content/uploads/2013/03/ Agenda-legislativa-2013-Povos-Indigenas.pdf>. Acesso em: 23 set. 2013.

Discursos e notas taquigráficas - orador Alcen Moreira, 20/11/2013c. Disponível em: <http://www.camara.leg.br/internet/sitaqweb/TextoHTML.asp ? etapa $=2 \&$ nuSessao $=378.3 .54$. O \&nuQuarto $=80 \&$ nuOrador $=3 \&$ nuInsercao $=0$ \&dtHorarioQuarto=16:42 \&sgFaseSessao=GE\%20\%20\%20\%20\%20\%20\%20\%20 \&Data $=20 / 11 / 2013 \&$ txApelido=ALCEU\%20MOREIRA\&txFaseSessao=Grande $\% 20$ Expediente $\% 20 \% 20 \% 20 \% 20 \% 20 \% 20 \% 20 \% 20 \% 20 \% 20 \% 20 \% 20 \% 20$ \&dtHoraQuarto=16:42\&txEtapa $=$ Sem\%20supervis\%C3\%A3o $>$. Acesso em: 21 nov. 2013.

CAPIBERIBE, A.; BONILLA, O. Um gosto amargo de déja vu: desenvolvimento e os índios. Le Monde Diplomatique Brasil, dez. 2012. Disponível em: <http://www.diplomatique.org.br/artigo.php?id=1308>. Acesso em: 13 set. 2013. 
CAPIBERIBE, A.; BONILLA, O. O rolo compressor ruralista: Projetos de lei, decretos e outros instrumentos legais relativos a direitos das populações indígenas (relação não exaustiva). Brasil de Fato, dez. 2013. Disponível em: <http://www.brasildefato.com. br/node/26920>. Acesso em: 18 ago. 2014.

CARNEIRO DA CUNHA, M. Política indigenista no século XIX. In: (Org.) História dos indios no Brasil. 2.ed. São Paulo: Cia. da Letras; Secretaria Municipal de Cultura; Fapesp, 1992. p.133-54.

Cultura com aspas. São Paulo: Cosac \& Naify, 2009.

CIMI. Relatório Violência contra os Povos Indigenas no Brasil: 2012. Disponível em: <http://www.cimi.org.br/pub/viol/viol2012.pdf>. Acesso em: 24 set. 2013.

CLASTRES, P. A sociedade contra o Estado. Trad. Theo Santiago. 4.ed. Rio de Janeiro: Francisco Alves, 1978.

CPT NACIONAL (CANUTO, A.; LUZ, C. R. da S.; LAZZARIN, F. (Org.)) Conflitos no campo - Brasil 2012. Disponível em: <http://www.cptnacional.org.br/index. php/component/jdownloads/finish/43-conflitos-no-campo-brasil-publicacao/316-conflitos-no-campo-brasil-2012? Itemid=23>. Acesso em: 21 nov. 2013.

DALLARI, D. Advocacia e ilegalidade anti-indio. 2012. Disponível em: <http://www. jb.com.br/sociedade-aberta/noticias/2012/07/27/advocacia-e-ilegalidade-anti-indio/>. Acesso em: 24 set. 2013.

DIAP. Bancada ruralista aumenta com o reforço de novos parlamentares. 2011. Disponível em: <http://www.diap.org.br/index.php/radiografia-do-congresso/bancadas-suprapartidarias/ruralista>. Acesso em: 13 set. 2013.

GRUNBERG, G.; MELIÀ, B. (Ed.) Guarani Retã. Povos Guarani na Fronteira Argentina, Brasil e Paraguai. UnaM/Endepa/CTI/Cimi/ISA/UFGD/Cepag/Conapi/SAI/GAT/SPASAJ/Capi. 2008 Disponível em: <http://pib.socioambiental.org/ files/file/PIB_institucional/caderno_guarani_\%20portugues.pdf>. Acesso em: 26 set. 2013.

KOPENAWA, D.; ALBERT, B. La chute du ciel: paroles d'un chaman Yanomami. Paris: Terre Humaine; Plon, 2010.

LATOUR, B. Guerre des mondes - offres de paix. In: BENETTO, J. V. (Org.) Volume spécial de l'Unesco. 2001. Disponível em: <http://www.bruno-latour.fr/sites/default/ files/81-GUERRE-PAIX-UNESCO-FR.pdf>. Acesso em: 26 set. 2013.

LÉVI-STRAUSS, C. A lição de sabedoria das vacas loucas. Trad. Nádia Farage. Comciência, 2009. Disponível em: <http://www.comciencia.br/comciencia/handler.php?se ction $=8 \&$ edicao $=46 \&$ \&id $=546>$. Acesso em: 26 set. 2013 .

LIMA, A. C. de S. O governo dos índios sob a gestão do SPI. In: CUNHA, M. C. da. (Org.) História dos indios no Brasil. 2.ed. São Paulo: Cia. da Letras; Secretaria Municipal de Cultura; Fapesp, 1992. p.155-72.

MONTEIRO, J. M. Negros da terra: índios e bandeirantes nas origens de São Paulo. São Paulo: Cia. das Letras, 1994.

PEREIRA, L. M. Demarcação de terras, reordenamentos organizacionais e gestão territorial. In: RICARDO, B.; RICARDO, F. (Org.) Povos indigenas no Brasil 2006/2010. São Paulo: Instituto Socioambiental, 2012a. p.688-91. 
PEREIRA, L. M. Expropriação dos territórios kaiowá e guarani: implicações nos processos de reprodução social e sentidos atribuídos às ações para reaver territórios - tekoharã. Revista de Antropologia da UFSCar, v.4, n.2, p.124-33, jul.-dez. 2012 b.

PERRONE-MOISÉS, B. Índios livres e índios escravos: os princípios da legislação indigenista do período colonial (séculos XVI a XVIII). In: CUNHA, M. C. da. (Org.) História dos Índios no Brasil. 2.ed. São Paulo: Cia. da Letras; Secretaria Municipal de Cultura; Fapesp, 1992. p.115-32.

PIGNARRE, P.; STENGERS, I. La sorcellerie capitaliste: Pratiques de désenvoûtement. Paris: La Découverte, 2007.

PIGNATI, W. Os riscos, agravos e vigilância em saúde no espaço do desenvolvimento do agronegócio no Mato Grosso. 2007. Tese (Doutorado) - Fundação Osvaldo Cruz/ENSP. Rio de Janeiro, 2007.

PIMENTEL, S. Cosmopolítica kaiowá e guarani: uma crítica ameríndia ao agronegócio. Revista de Antropologia da UFSCar, v.4. n.2, p.134-50, jul.-dez. 2012.

Violação dos direitos humanos e a luta pela terra - Guarani-Kaiowa: pouca terra, muitos índios, muita tragédia. In: VENTURI, G.; BOKANY, V. (Org.) Povos indígenas. São Paulo: Fundação Perseu Abramo, 2013.

Aty Guasu, as grandes assembleias kaiowá e guarani: os indígenas de MS e a luta pela redemocratização do país. In: CHAMORRO, G.; COMBÉS, I. (Org.) Povos indigenas no Mato Grosso do Sul. Dourados: Ed. UFGD (no prelo).

PIMENTEL, S.; MONCAU, J. Guarani-Kaiowá - genocídio surreal. In: RICARDO, B.; RICARDO, F. (Ed.) Povos Indigenas no Brasil 2006/2010. São Paulo: Instituto Socioambiental, 2012. p.692-96.

SAKAMOTO, L. (Coord.) Impactos da soja sobre terras indigenas no Mato Grosso. Centro de Monitoramento de Agrocombustíveis. São Paulo: Repórter Brasil, 2010. <http://reporterbrasil.org.br/documentos/indigenas_soja_MT.pdf>. Acesso em: 25 set. 2013.

SCHLESINGER, S. (Org.) Dois casos sérios em Mato Grosso: a soja em Lucas do Rio Verde e a cana-de-açúcar em Barra do Bugres. 2013. Disponível em: <http://www. formad.org.br/wpcontent/uploads/2013/06/LIVRO_dois_casos_serios_agrocombustiveis_FORMAD.pdf>. Acesso em: 25 set. 2013.

SOUTO MAIOR, A. P. C. Desafios indígenas no Congresso Nacional. In: RICARDO, B.; RICARDO, F. (Ed.) Povos indigenas do Brasil: 2006-2010. São Paulo: Instituto Socioambiental, 2011. p.66-8.

SPAROVEK, G. et al. Considerações sobre o Código Florestal Brasileiro. 2010. Disponível em: <http://www.ekosbrasil.org/media/file/OpCF_gs_010610_v4.pdf>. Acesso em: 25 set. 2013 .

STENGERS, I. Au temps des catastrophes. Résister à la barbarie qui vient. Paris: La Découverte, 2009.

STF (SUPREMO TRIBUNAL FEDERAL). Petição 3.388/RR [ementa, acórdão, relatório e votos]. Revista Trimestral de Jurisprudência, vol. 212: 49-371, 2010. Disponível em: <http://www.stf.jus.br/arquivo/cms/publicacaoRTJ/anexo/212_l.pdf>. Acesso em: 18 nov. 2013. 
STF (SUPREMO TRIBUNAL FEDERAL). Petição 3.388/RR - Acompanhamento processual. 2013. Disponível em: <http://www.stf.jus.br/portal/processo/verProcessoAndamento.asp? incidente $=2288693>$. Acesso em: 20 nov. 2013.

THOMAZ DE ALMEIDA, R. Relatório geral sobre a área indígena Guarani Pai-Kaiowá do Rio Iguatemi - MS. Funai, 1984. (mimeo.).

VIANNA, L. W. Razões para um mundo fora do eixo. O Estado de S. Paulo, 2013, p.A2. Disponível em: <http://www.estadao.com.br/noticias/impresso,razoes-para-um--mundo-fora-do-eixo-,1067578,0.htm>. Acesso em: 23 ago. 2013.

VIVEIROS DE CASTRO, E. Os termos da outra história. In: RICARDO, C. A. (Ed.) Povos indígenas do Brasil: 1996-2000. São Paulo: Instituto Socioambiental, 2000. p.4954.

VV. AA. Palavras indígenas: doze narrativas sobre a origem do mundo, a chegada dos brancos e os 500 anos do Brasil. In: RICARDO, C. A. (Ed.) Povos indigenas do Brasil: 1996-2000. São Paulo: Instituto Socioambiental, 2000. p.18-48.

YAMADA, E. M.; VILLARES, L. F. Julgamento da terra indígena Raposa Serra do Sol: todo dia era dia de índio. Revista Direito GV, v.6, n.1, p.143-57, 2010. Disponível em: <http://www.scielo.br/scielo.php?pid=S1808-24322010000100008\&script=sci_arttext>. Acesso em: 30 ago. 2013.

. Quem ganha com conflitos não resolvidos?. In: RICARDO, B.; RICARDO, F. (Ed.) Povos indigenas do Brasil: 2006-2010. São Paulo: Instituto Socioambiental, 2011. p.61-2.

RESUMO - Este artigo explora o embate entre política e modelo econômico presente na atual luta das populações indígenas pelo reconhecimento e garantia de seu modo de vida. A terra é basicamente a questão em torno da qual se mobilizam as tensões voltadas aos índios. Na base dessas, o que há são modelos de relacionamento com os entes do planeta (fauna, flora, humanidade) radicalmente opostos. É do enfrentamento político entre esses modelos que o artigo trata, trazendo à luz a peleja dos índios com o agronegócio e seus representantes no Congresso Nacional, exposta de maneira radical quando os índios ocuparam o plenário da Câmara Federal, em abril de 2013. Busca-se aqui destacar a importância atual do campo normativo como espaço de disputa na caução de direitos, assim como a influência do protagonismo político indígena.

Palavras-CHAVE: Povos indígenas, Congresso Nacional, Terras indígenas, Legislação, Agronegócio.

ABSTRACT - This article explores the confrontation between the politics and economic model inherent in the present-day struggle of the indigenous people for recognition and guarantees of their way of life. Land is the basic issue around which tension with respect to the Indians cristalize. At the heart of the question are radically opposing models of the relationship between the forms of life on the planet (fauna, flora, humanity). This article focuses on the political confrontations between these models, shedding light on the Indian's struggle against agribusiness and its representatives in the National Congress, radically exposed when the Indians occupied the Federal Chamber of Depu- 
ties in April 2013. The objective is to highlight the contemporary importance of the normative field as a space to dispute the guarantee of rights, as well as the influence of indigenous political protagonism.

KEYWORDS: Indigenous peoples, National Congress, Indigenous lands, Legislation, Agribusiness.

Artionka Capiberibe é antropóloga, professora do Departamento de Antropologia do Instituto de Filosofia e Ciências Humanas da Universidade de Campinas (IFCH/Unicamp). @-artionka@yahoo.com.br

Oiara Bonilla é antropóloga, professora do Departamento de Antropologia do Instituto de Ciências Humanas e Filosofia da Universidade Federal Fluminense (ICHF/UFF) e pesquisadora associada ao Centre d'Enseignement et de Recherche en Ethnologie Aaméricaniste (EREA/LESC, Université Paris Ouest-Nanterre La Défense).

@ - oiarabonilla@gmail.com

Recebido 24.3.2014 e aceito em 21.8.2014.

I Instituto de Filosofia e Ciências Humanas, Universidade de Campinas, Campinas/SP, Brasil.

II Instituto de Ciências Humanas e Filosofia, Universidade Federal Fluminense, Niteroi/RJ, Brasil. 
